\title{
BEHAVIOR IN UNCERTAIN ENVIRONMENTS, AND PRONE TO RISK OR CAUTION
}

\author{
Ilona Kalva, Dmitry Shyryaev \\ Baltic Psychology and Management University College, Riga, Latvia \\ E-mail: kalva_i2@inbox.lv, glanceltd@gmail.com
}

\begin{abstract}
The purpose of this study was to appreciate the possibility to use the method of study of probabilistic forecasting for staff selection needs. Indicators of probabilistic forecasting, prone to risk were studied in a stochastic environment. This is a pilot study, because a well known technique: Bayesian logic applied to decision making with probability inference - using the knowledge of prior events to predict future events - in the new modification was used. The novelty lies in the fact that, besides the opportunity to study the prognostic abilities of the brain in a situation of uncertainty, was made an attempt to study the impact on the forecasting process of emotions associated with possible monetary gain or loss. Differences in effectiveness and dynamics of probabilistic activity were revealed in persons with differing extent of gain and temperament type.
\end{abstract}

Key words: individual differences, probability learning risky behavior, type of temperament.

\section{Introduction}

The theme of probabilistic forecasting is an inexhaustible source for scientific studies: the probability learning design have been widely used since the 19th century. This approach enables to analyze in general, a person's ability to estimate the probabilities and particularities of taken decisions. Depending on the scientific research paradigm, which examines the behavior in an uncertain environment, different techniques are used and the results analyzed in terms of decision theory, game theory or in terms of economy and applied psychology (Kaneman, 2004; Birnbaum, 2008; Aczel, 2009; Birnbaum, 2012). The psychophysiological and neuropsychological studies focus on the brain structures involved in the process of predicting (Chun Siong Soon, Marcel, Heinze, Haynes, 2008; Kuhnen, Knutson, 2005). These various studies have in common treir concepts: both decisionmaking concept and forecasting the future concept, in fact, are closely related with the concept of uncertainty and the desire to reduce the uncertainty for improving the psychological and physical well-being. Therefore to understand how people learn probabilistic information is a fundamental question of human behaviour. 
A person makes a decision on the basis of a subjective model of the current situation. This model inevitably contains elements of uncertainty for two reasons: the person does not possess complete knowledge about the world and in the world there is an objective randomness of events. Looking for algorithms work, the person must first support on the frequency characteristics of the events - the primary stage of the analysis of environment (Ширяев, 2001). So, the decision is made usually in a lack of information and involves speculations and predictions of future events. Studies show that professionals and nonspecialists accept the same mistakes when making decisions (Halpern, 2000). To which extent decision-making depends on the consciousness, knowledge, skills, personality traits, characteristics of an organism?

Despite the longstanding existence of the unique design of binary predictions, the order of application of the probabilistic forecasting procedure is different in many studies, making it difficult to compare the results, especially in terms of individual differences.

\section{Research Focus}

The present study investigates the fundamental processes of the brain - the cognitive processes that have multiple levels. The most primary of which is the reveal the regularities, that is, determine the frequency of the events of the environment (Ширяев, 1996). There are studies that examined cognitive and personality-motivational factors of decision-making, but they are treated as variables distorting rational decision-making strategy (Kaneman, 2004). Cognitive component of decision-making process, using a probabilistic design training, also had been studied under time preasure (Godie, Crooks, 2004). The time factor reduced performance in tasks of making a decision, presumably because of the involvement of heuristic processes. In Simmon, Nelson (2006) study, devoted to the study of probability learning, it was shown that influence of the intuitive component (subjective confidence in the choist of alternatives) is not inevitable, but it is determined by contextual variables that affect intuitive confidence. "A change in focus from "consciousness" to "attention" in future investigations and descriptions such as computational models, may yield considerably more advances in research on human learning and decision making" (Aczel, 2009, p. 211). The subject of the present study is a structure of psychic self-regulation of human behavior under uncertainty, based on two components: risk aversion and prudence (caution). The idea is to combine a well-worked research method (modeling a stochastic environment of two alternatives) with a more meaningful game situation, with the awareness of additional risk of possible losses or gains. It was supposed to reveal a correlation between the effectiveness of forecasting and personal characteristics. It was supposed to identify individuals as risk-averse and "cautious" or risk-avoid.

\section{Methodology of Research}

\section{General Background of Research}

In the probability learning or probability guessing paradigm, the judge's task is to predict, to guess, or choose which of two or more events will occur on the next instance. For example, the person might be asked to predict whether the next card drawn randomly from a shuffled deck will be red or black. The classic result in this task is known as probability matching, a tendency by the participant to match the probability of choosing the responses to the probability that each response has been reinforced, or shown to be right (Birnbaum, 2012). One of well known researching methods in psychophysiology of probability learning was elaborated and descripted by J.Feigenberg (1969) (cited after Shyryaev (Ширяев, 1986). Particularly, this method was based on Bayesian logic applied to decision making in situation of uncertainty. In modern studies this approach is named as probability learning design. 


\section{Sample of Research}

In the first series of a pilot study in a group of 12 students the relationship between probabilisticprediction indicators and the value of "rates" in the conventional monetary units for each winor loss was investigated, as well as their relation to personality factors in the decision-making "rational"and "readiness to take risks" by T.Kornilova (Корнилова, 2003). In the second series of a pilot study in a group of 87 students the association of predictions and temperament was examined. Each respondent first took probability-prognostic test (Ширяев, 2001), then LFR-25 and Eysenck tests.

\section{Instrument and Procedures}

To study the predictive probability the signal sequence was presented from two alernative signals (the letters A and B), in random order. 25:75 ratio of alternatives, a total of 100 signals. Prognostic indicators of activity were calculated: subjective probability of alternatives, effectiveness of prediction (confirmed predictions of each alternatives), dynamics of probability learning in 4 consecutive sections of the signal Sequence, consisting of 25 signals. Further, the dynamics of learning, reflection of the adequacy of the probabilistic structure of the stochastic environment (strategy of forecasting - probabilistic matching, indifference or maximization) was assessed.

To study the effect of possible monetary gain or loss previously agreed that before every forecast made bets (options: 10, 20 and 50 conventional monetary units). The procedure is like the casino. Firstly, a voice command "make your bets" was given. Then the voice command "forecast" was given, then - a visual signal of the letter was presented, and the subjects could see the success or failure of his prediction, time to recognize gain or loss. The time interval between the end of one command and the beginning of the next 5 seconds. In general, a con game was given to 20-24 seconds. The entire game "casino" took about 40 minutes. To study the personal characteristics after the prediction the survey was conducted (Корнилова, 2003). To study the temperament the famous test by Eysenck was used.

\section{Data Analysis}

Data of probabilistic forecasting and personality tests were processed statistically using EXCEL and SPSS. The Spearman correlation coefficients were calculated between indicators of prognostic activity and personal characteristics. An intragroup differences (by U-criteria of the Wilcoxon-MannWhitney) accordingly to different indicators (probability learning rate, the adequacy of the probabilistic structure reflected, a readiness of risk-taking, the type of temperament) were calculated.

\section{Results of Research}

The results of the 1st series showed that the value of winning in a game related to the number of forecasts of rare alternative $\left(\mathrm{r}=-0.766^{* *}\right)$. And more strong correlation of winning size was for expected frequency of rare alternative $\left(\mathrm{r}=0.830^{* *}\right)$. Non remarkable correlations were found for "rationality" and "risk readiness" with forecasting parameters.

Then the $1^{\text {st }}$ group was split into 2 subgroups by the size of win: 6 persons with high gains and 6 persons with low gain or lost. The groups did not differ by their "risk readiness" scores, but they differed by scores of rationality. Those who have high winnings had high score of rationality after U- criterion.

The results of the $2^{\text {nd }}$ series were processed separately for each of 4 temperament groups. Comparative analysis showed differences in efficiency of predicting and adequacy of reflecting of uncertain environment structure. 


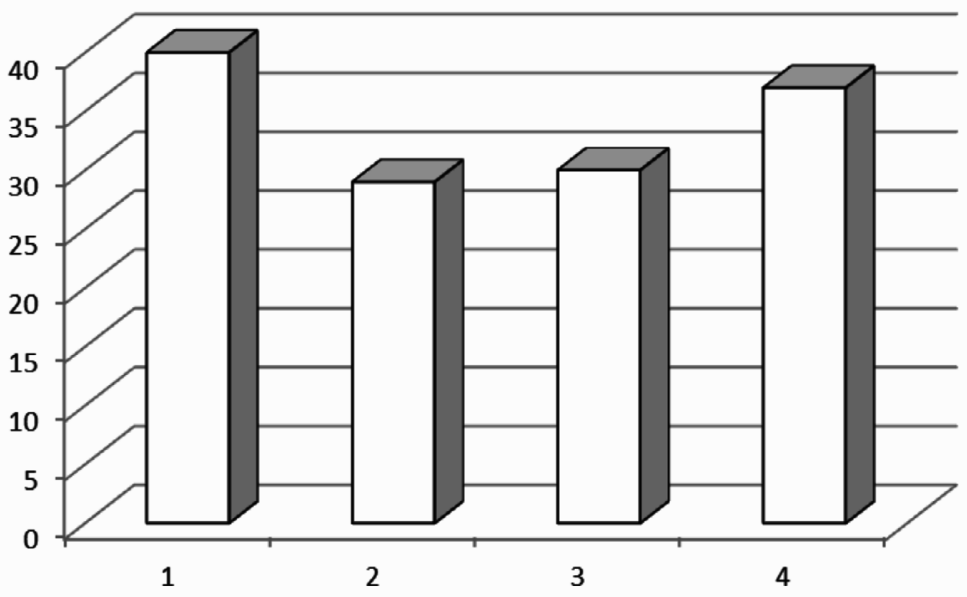

Figure 1. The frequency of choice of a rare event in choleric (1), sanguine (2), phlegmatic (3) and melancholic (4).

Owners of phlegmatic and sanguine temperament demonstrated more precise reflection of frequency of rare alternative - below 30 (given ratio 25:75) (Figure 1). As well these persons demonstrated higher efficiency of predicting - above 65 percent, in comparison with cholerics and melancholics- between 61 and 60 percent. (Figure 2).

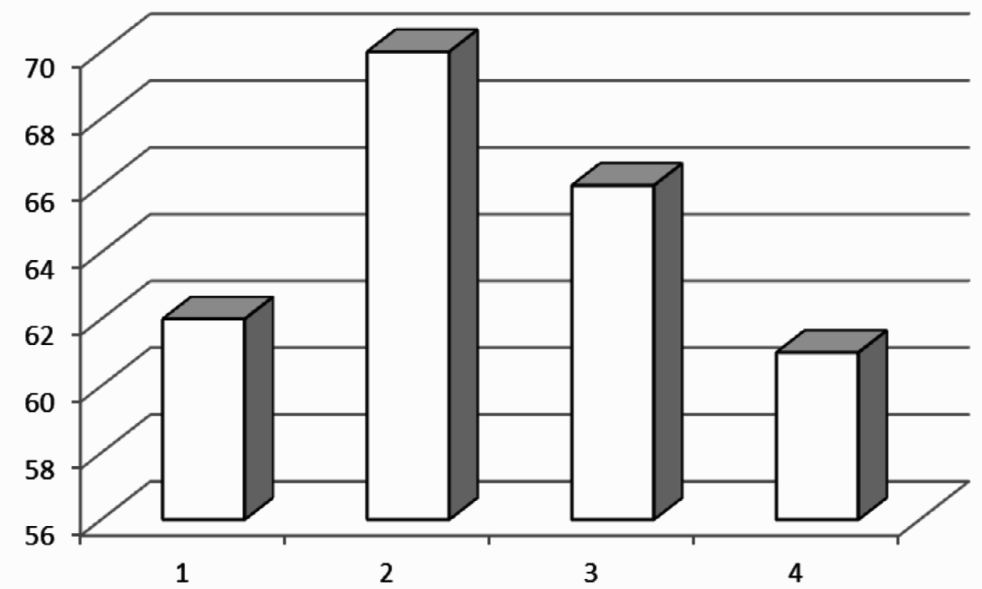

Figure 2. The overall effectiveness of forecasting by choleric (1), sanguine (2), phlegmatic (3) and melancholic (4).

\section{Discussion}

The results showed that the method of "guessing game" where you want to predict the emergence of alternative signals A and B (with ratio 25:75) are imposed in a random sequence, that is convenient and informative in order to identify individual differences. This pilot study revealed differences between representatives of temperament types referring to dynamics of the probabilistic learning and characteristics of the probabilistic structure reflecting. It was shown that the main feature that correlated with individual differences in prognostic activity had been the degree of neuroticism. In the literature, only a few papers were found in this direction, but there are still confirming the results obtained by the authors : in multiple regression analyses, neuroticism was negatively associated with IOWA Gambling Test performance among males (Hooper at all, 2008). At least, Garon\& Moore (2006) at the basis of gained results suggest a complex association between IOWA Gambling Test performance and temperament in preschoolers (Garon, Moore, 2006). Results of tpy present study coincide with literature data about relations between level of neurotism and risk propensity (Cooper, 
2003).These information reinforces the belief that the typological features of the nervous system are indeed a significant factor influencing the self-regulation of behavior in situations of uncertainty. In occupations where employees meet regularly with risky situations, extremal or some other kind of high uncertainty, they should be aware of risk degree, be also capable of rapid decision making, adequate assessment of the probabilistic structure of the environment, to apply so-called minimax behavior strategy in an effort to minimize the possible risk (and thus its losses) and at the same time maximize the gain. According to the model of the present study a minimax strategy means that a person must make the greatest wins, while trying not to "slip" on a strategy of forecasting, which is called maximizing. When maximizing a person ignores a rare alternative, because they realize bigger benefit while more guessing frequent signals (Ширяев, 2001). And if this was not a game situation, but operator type of work, where both of signals have to be predicted, then neglect of the rare alternative could lead to disaster. There in the paper presented by Shlyakhtina (Шляхтина, 2004) people using minimal rates in a game situation as a card game, have been named cautious. However, the results of the present study showed that people are making big gains in different ways: combining different prediction strategies and tactics, as well as in the way of preference for high or low stakes. Some are successful, maximizing frequent alternative, while others, especially making several forecasts of rare alternative in a row. Therefore, the concept of caution, or prudence, may be considered as more complicated psychological construct, related both with personality features, as well with typological features of the nervous system. Temperament undoubtedly plays a role in this process. Owners of a weak nervous system must be psychologically more sensitive to losses experienced. So they try not to ignore the rare alternative, but on the contrary - to forecast several rare events in a row.

\section{Conclusions}

The opportunity to study prognostic abilities of the brain as well personal prone to risk and a role of temperament together in a situation of uncertainty was tested.

It was shown that in a model of a casino game situation (predicting each of alternative signals, presented in random order) big gains may be achieved in different ways: combining prediction strategies and tactics, as well as a preference for high or low stakes.

The efficiency of probabilistic forecasting depends on the personal rationality and type of temperament. It is needed complex assessment of different indicators of probabilistic activity and personality features for emerging of those persons who will be efficient, adequate and cautious in the situation of uncertainty.

The results confirm that modified method of probability matching would be a correct way for further investigation of the probabilistic activity of the brain.

\section{References}

Aczel, B. (2009). Attention and Awareness in Human Learning and Decision Making. A Dissertation Submitted for the Degree of Doctor of Philosophy. Cambridge: University of Cambridge. Retrieved from: http:// www.dspace.cam.ac.uk/bitstream/1810/224472/1/BalazsAczel_PhD_Thesis_2009.pdf

Birnbaum, M. H. (2008). New Paradoxes of Risky Decision Making. Psychological Review, 115 (2), 463501.

Birnbaum, M. H. (2012). Perspective on judgment and decision making as a skill. In M. K. Dhami, A. Schlottmann, \& M. R. Waldmannn (Eds.), Judgment and decision making as a skill (pp. 302-303). New York: Cambridge University Press.

Chun Siong Soon, Brass, M., Heinze, H. J., Haynes, J. D. (2008). Unconscious determinants of free decisions in the human brain. Nature Neuroscience, 11 (5), 543-545.

Cooper, D. (2003). Understanding how personality \& perception can influence risk taking. Professional safety, Journal of the American Society of Safety Engineers, 11, 39-46. Retrieved from http://www.asse.org/.

Garon, N., Moore, C. (2006). Negative Affectivity Predicts Individual Differences in Decision Making for Preschoolers. Journal of Genetic Psychology, 167 (4), 443-462. 
Godie, Adam S., Crooks, C. L. (2004). Time-Pressure on Performance in a Base-Rate Task. Journal of General Psychology, 131 (1), 18-28.

Hooper, C., Luciana, M., Wahlstrom, D., Conklin, H., Yarger, H. (2008). Personality correlates of Iowa Gambling Task performance in healthy adolescents. Personality \& Individual Differences, 44 (3), 596-607.

Kaneman, D. (2004). Freud, finance and folly. Economist, 370 (8359), 5-6.

Kuhnen, C. M., Knutson, B. (2005). The Neural Basis of Financial Risk Taking. Neuron, 47, 763-770.

Simmons, J. P., Nelson, L. D. (2006). Intuitive confidence: choosing between intuitive and nonintuitive alternatives. Journal of Experimental Psychology, 135 (3), 409-28.

Корнилова, Т. В. (2003). Психология риска и принятия решений. Москва: Аспект Пресс.

Ширяев, Д. А. (1986). Психофизиологические механизмы вероятностного прогнозирования. Рига: Зинатне.

Ширяев, Д. А. (2001). Роль функциональной асимметрии мозга в процессе вероятностного прогнозирования. Актуальные проблемы психологии: теория и практика (с.196-217). Рига: БРИ, ВШП.

Халперн, Д. (2000). Психология критического мышления. Санкт Петербург: Питер. (Original work Halpern Diane F. (1996).

Шляхтина, Е. Г. Индивидуальные особенности принятия решений в условиях риска и их взаимосвязь с личностными характеристиками. Retrieved from http://www.unn.ru/pages/issues/vestnik/99990201_ West_soc_2004_1(3)/10.pdf.

Advised by Julia Lakhvich, Belarusian State University, Republic of Belarus

Received: May 08, 2012

Accepted: June 19, 2012 